\section{Herman Rante}

Magister IImu Pemerintahan Universi-

tas Muhammadiyah Yogyakarta

Email: hr_daffa@yahoo.co.id

\section{Dyah Mutiarin}

Dosen Magister Ilmu Pemerintahan Universitas Muhammadiyah Yogyakarta

Email: dyahmutiarin@umy.ac.id

http://dx.doi.org/10.18196/

jgpp.2016.0048
Persepsi Masyarakat Terhadap Layanan Badan Penyelenggara Jaminan Sosial Kesehatan di RSUD Morangan Sleman DIY

\begin{abstract}
Act No. 24 of 2011 is in force since one January 2014 throughout the local government, is no exception Sleman Yogyakarta. However, implementation of this BPJS still encountered many problems in the field. But the booming community participation has not been matched by an adequate system so much going problems field. Moreover, lack of socialization by BPJS cause the crux of information in society. In addition, a lot of complaints from health insurance participants who feel lost its facilities, especially in the referral process, medicines and other support services. The purpose of this study was to determine how the implementation BPJS Sleman district in managing the National Health Insurance in Sleman. This research is descriptive quantitative research. Data collection techniques in this study questionnaire and documentation techniques. As for the number of samples in this study were 100 people with purposive sampling technique. The technique used to analyze the data in this study is the analysis technique by using the index and Test Independent Sample T test using SPSS software. Based on the results of this study concluded that the public perception of the Institution of Social Security ministry of health in hospitals Morangan Sleman Yogyakarta based on Article 10 of Act No. 24 of 2011 which consists of 1) Conduct and / or receiving Participant registration, 2) Picking up and collecting dues from participants and Employers, 3) Receive contribution of Government assistance, 4) Collect and manage data participants Social Security program, 5) Paying Benefits and / or pay for health services in accordance with the provisions of the Social Security program and 6) Provide information regarding the conduct of the Social Security program the participants and the community has been good with a range of index values of $2.78 \mathrm{~s} / \mathrm{d}$ 3.43. The results of this study also concluded that 1) there was no significant difference in perception between the groups of beneficiaries and the contribution of non beneficiaries of contributions based on the implementation and or accept registration of participants in the Health BPJS Sleman.2) there was no significant difference in perception between the groups receiving communities tuition assistance and contribution of non beneficiaries based data management BPJS participants in Sleman. 3) there are significant differences in perceptions between groups of beneficiaries dues and non-beneficiary communities dues by the payment of benefits or pay for health services BPJS in Sleman and 4) there are significant differences in perceptions between groups of beneficiaries and the contribution of non beneficiaries dues based on the implementation of information provision BPJS Sleman Key Words: Implementation, Social Security Programs and BPJS
\end{abstract}

\footnotetext{
ABSTRAK

Undang-undang No 24 tahun 2011 ini diberlakukan sejak 1 Januari 2014 diseluruh pemerintah daerah, tidak terkecuali Kabupaten Sleman Daerah Istimewa Yogyakarta. Namun demikian pelaksanaan BPJS ini masih menemui banyak permasalahan di lapangan. Membludaknya partisipasi masyarakat belum diimbangi dengan sistem yang memadai sehingga dilapangan banyak terjadi permaslahan. Terlebih lagi kurangnya sosialisasi oleh BPJS menyebabkan terjadinya
} 
kesimpang siuran informasi di masyarakat. Selain itu banyak sekali komplain dari peserta askes yang merasa kehilangan fasilitasnya terutama dalam proses rujukan, obat-obatan dan layanan pendukung lainnya. Tujuan dari penelitian ini adalah untuk mengetahui bagaimana implementasi BPJS Kabupaten Sleman dalam dalam mengelola Jaminan Kesahatan Nasional (JKN) di Kabupaten Sleman. Jenis penelitian ini adalah penelitian deskriptif kuantitatif. Teknik pengumpulan data dalam penelitian ini teknik kuisoner dan dokumentasi. Adapun jumlah sampel dalam penelitian ini adalah 100 orang dengan teknik pengambilan sampel purposive sampling. Teknik yang digunakan untuk menganalisa data dalam penelitian ini adalah teknik analisis dengan menggunakan indeks dan Uji Independent Sample T test dengan menggunakan Software SPSS Berdasarkan hasil penelitian dapat disimpulkan bahwa persepsi masyarakat terhadap layanan badan penyelenggara jaminan sosial kesehatan di RSUD Morangan Sleman DIY berdasarkan Pasal 10 undang-undang No 24 tahun 2011 yang terdiri dari 1) Melakukan dan/atau menerima pendaftaran Peserta, 2) Memungut dan mengumpulkan luran dari Peserta dan Pemberi Kerja, 3) Menerima Bantuan luran dari Pemerintah, 4) Mengumpulkan dan mengelola data Peserta program Jaminan Sosial, 5) Membayarkan Manfaat dan/atau membiayai pelayanan kesehatan sesuai dengan ketentuan program Jaminan Sosial dan 6) Memberikan informasi mengenai penyelenggaraan program Jaminan Sosial kepada Peserta dan masyarakat sudah baik dengan rentang nilai indeks 2,78 s/d 3,43. Hasil penelitian ini juga menyimpulkan bahwa 1) tidak ada perbedaan persepsi yang siginifikan antara golongan masyarakat penerima bantuan iuran dan masyarakat non penerima bantuan iuran berdasarkan pelaksanaan dan atau menerima pendaftaran peserta BPJS Kesehatan di Sleman.2) tidak ada perbedaan persepsi yang siginifikan antara golongan masyarakat penerima bantuan iuran dan masyarakat non penerima bantuan iuran berdasarkan pengelolaan data peserta BPJS Kesehatan di Sleman. 3) ada perbedaan persepsi yang siginifikan antara golongan masyarakat penerima bantuan iuran dan masyarakat non penerima bantuan iuran berdasarkan pembayaran manfaat atau membiayai pelayanan kesehatan BPJS Kesehatan di Sleman dan 4) ada perbedaan persepsi yang siginifikan antara golongan masyarakat penerima bantuan iuran dan masyarakat non penerima bantuan iuran berdasarkan pemberian informasi penyelenggaraan BPJS Kesehatan Sleman.

Kata Kunci: Implementasi, Program Jaminan Sosial dan BPJS

\section{PENDAHULUAN}

Badan Penyelenggara Jaminan Sosial (BPJS) yang telah dibentuk berdasarkan Undang-Undang Nomor 24 Tahun 2011 Tentang BPJS yang merupakan transformasi dari empat Badan Usaha Milik Negara (Askes, ASABRI, Jamsostek dan Taspen). Melalui Undang-Undang No 24 tahun 2011 ini, maka dibentuk 2 (dua) BPJS, yaitu BPJS Kesehatan dan BPJS Ketenagakerjaan. BPJS Kesehatan menyelenggarakan program jaminan kesehatan dan BPJS Ketenagakerjaan menyelenggarakan program jaminan kecelakaan kerja, jaminan hari tua, jaminan pensiun, dan jaminan kematian. Dengan terbentuknya kedua BPJS tersebut maka jangkauan kepesertaan program jaminan sosial akan diperluas secara bertahap (Qomaruddin, 2012).

Undang-Undang No 24 tahun 2011 mewajibkan pemerintah untuk memberikan lima jaminan dasar bagi seluruh masyarakat Indonesia yaitu jaminan kesehatan, kecelakaan kerja, kematian, pensiun, dan tunjangan hari tua. Jaminan dimaksud akan dibiayai 
oleh 1) perseorangan, 2) pemberi kerja, dan/atau 3) Pemerintah. Dengan demikian, Pemerintah akan mulai menerapkan kebijakan Universal Health Coverage dalam hal pemberian pelayanan kesehatan kepada masyarakat, dimana sebelumnya Pemerintah (Pusat) hanya memberikan pelayanan kesehatan bagi Pegawai Negeri Sipil dan ABRI-Polisi (Janis, 2014).

Dibentuknya Undang-Undang No 24 tahun 2011 untuk keperluan tata kelola penyelenggaraan jaminan sosial yang efektif bagi seluruh warga Negara Indonesia ternyata dalam implementasinya masih banyak ditemukan kendala dilapangan. Pertama, masalah pengadaan obat-obatan. Sebelum BPJS kesehatan diberlakukan, pasien diberikan obat untuk jangka waktu 30 hari. Namun setelah BPJS kesehatan diberlakukan, pasien hanya diberikan obat dalam jangka waktu 7 hari. Kedua masih banyak rumah sakit swasta yang belum bergabung pada BPJS kesehatan, terutama di daerah. Kurangnya sosialisasi menjadi penyebab utama belum bergabungnya rumah sakit swasta menjadi jejaring BPJS kesehatan (www.beritasatu.com).

Undang-undang No 24 tahun 2011 ini diberlakukan sejak 1 Januari 2014 diseluruh pemerintah daerah, tidak terkecuali Kabupaten Sleman Daerah Istimewa Yogyakarta. Kabupaten Sleman pada saat ini telah memiliki 25 fasilitas pelayanan primer 25 Puskesmas, 48 dokter keluarga, 15 dokter gigi keluarga serta klinik pratama telah menandatangani perjanjian kerjasama dengan Badan Penyelenggara Jaminan Sosial. Fasilitas kesehatan rujukan ada 26 Rumah Sakit. Dari 26 rumah sakit, sebanyak 17 Rumah Sakit telah bekerjasama dengan BPJS. Namun demikian pelaksanaan BPJS ini masih menemui banyak permasalahan di lapangan. Membludaknya partisipasi masyarakat belum diimbangi sistem yang memadai sehingga dilapangan banyak terjadi permasalahan. Terlebih lagi kurangnya sosialisasi oleh BPJS menyebabkan terjadinya kesimpang siuran informasi di masyarakat. Selain itu banyak sekali komplain 
dari peserta askes yang merasa kehilangan fasilitasnya terutama dalam proses rujukan, obat-obatan dan layanan pendukung lainnya (www.slemankab.go.id)

Jumlah kepesertaan jaminan kesehatan di Kabupaten Sleman yang langsung dapat diintegrasikan dengan JKN kurang lebih 43,2\% dari jumlah penduduk Kabupaten Sleman yang berjumlah 1.059.383 jiwa. Diluar 40\% tersebut, masih terdapat kurang lebih 26,7\% yang juga memiliki jaminan kesehatan yang meliputi jamkesda Penerima Bantuan Iuran (PBI) dari APBD Kabupaten Sleman, yaitu berjumlah 143,191 jiwa Jamkesda untuk pamong desa, pegawai honorer dan kader kesehatan sebanyak 11.327 jiwa, Jamkesda mandiri sebanyak 19,470 jiwa, peserta Jamkesos miskin sebanyak 19.000 jiwa dan Jamkesos Kader sebanyak 7.503 jiwa dengan bantuan iuran dari APBD Propinsi dan 10\% prediksi penduduk yang memiliki jaminan kesehatan komersial lainnya (www.slemankab.go.id)

Setelah diberlakukannya undang-undang No 24 tahun 2011, maka tahab selanjutnya adalah implementasi dari undang-undang tersebut. Menurut Gaffar (2009) implementasi adalah suatu rangkaian aktifitas dalam rangka menghantarkan kebijakan kepada masyarakat sehingga kebijakan tersebut dapat membawa hasil sebagaimana yang diharapkan. Rifdan (2010) menambahkan bahwa implementasi kebijakan dalam konteks kebijakan publik adalah pelaksanaan dari suatu keputusan tertentu yang ditetapkan melalui undang-undang, peraturan pemerintah atau peraturan daerah untuk mencapai sasaran dan tujuan bersama dalam kehidupan bermasyarakat. Dengang demikian diperlukan implementasi dari undangundang No 24 tahun 2011 agar kebijakan yang telah disusun dapat secara langsung dirasakan manfaatnya oleh masyarakat.

Pasal 10 undang-undang No 24 tahun 2011 menyebutkan bahwa BPJS memiliki beberapa tugas yaitu 1) melakukan dan/atau menerima pendaftaran Peserta, 2) memungut dan mengumpulkan iuran dari Peserta dan Pemberi Kerja, 3) menerima Bantuan Iuran 
dari Pemerintah, 4) mengelola Dana Jaminan Sosial untuk kepentingan Peserta, 5) mengumpulkan dan mengelola data Peserta program Jaminan Sosial, 6) membayarkan manfaat dan/atau membiayai pelayanan kesehatan sesuai dengan ketentuan program Jaminan Sosial; dan 7) memberikan informasi mengenai penyelenggaraan program Jaminan Sosial kepada Peserta dan masyarakat.

Berdasarkan uraian di atas menunjukkan bahwa Kabupaten Sleman sudah memulai untuk mengimplementasikan undangundang No 24 tahun 2011. Hal ini ditunjukkan dengan adanya persiapan pemerintah kabupaten Sleman yang telah menyiapkan fasilitas kesehatan rujukan dari 26 Rumah Sakit yang ada sebanyak 17 Rumah Sakit telah bekerjasama dengan BPJS. Adanya persiapan ini menunjukkan bahwa Kabupaten Sleman telah siap untuk mengimplementasikan undang-undang No 24 tahun 2011 tentang BPJS.

Berdasarkan latarbelakang masalah di atas maka rumusan masalah yang menjadi fokus dalam penelitian ini adalah sebagai berikut:

1. Bagaimana persepsi masyarakat terhadap layanan badan penyelenggara jaminan sosial kesehatan di RSUD Morangan Sleman DIY?

2. Apakah ada perbedaan antara Penerima Bantuan Iuran (PBI) dan non Penerima Bantuan Iuran (PBI) dalam: Pelaksanaan dan atau menerima pendaftaran peserta BPJS kesehatan Kabupaten Sleman, pengelolaan data peserta BPJS kesehatan Kabupaten Sleman, pembayaran manfaat atau membiayai pelayanan kesehatan BPJS kesehatan Kabupaten Sleman, pemberian informasi penyelenggaraan BPJS kesehatan Kabupaten Sleman.

\section{KERANGKA TEORI}

\section{KEBIJAKAN PUBLIK}

Suharto (2007) dalam bukunya yang berjudul Kebijakan Sosial 
Sebagai Kebijakan Publik menyebutkan bahwa kebijakan (policy) adalah sebuah instrumen pemeritahan, bukan saja dalam arti goverment yang hanya menyangkut aparatur Negara, melainkan juga governance yang menyentuh pengelolaan sumber daya publik. Kebijakan pada intinya merupakan keputusan-keputusan atau pilihan-pilihan tindakan secara langsung mengatur pengelolaan dan pendistribusian sumber daya alam, finasial dan manusia demi kepentingan publik, yakni rakyat banyak, penduduk, masyarakat atau warga Negara. Kebijakan merupakan hasil dari adanya sinergi, kompromi atau bahkan kompetisi antara berbagai gagasan, teori, idoelogi, dan kepentingan-kepentingan yang mewakili sistem politik suatu Negara.

Bridgeman dan Davis (2004) menerangkan bahwa kebijakan publik sedikitnya memiliki tiga dimensi yang saling bertautan, yakni sebagai tujuan (Objective), sebagai pilihan tindakan yang legal atau sah secara hukum (Authoritative Choice), dan sebagai hipotesis (Hypothesis).

\section{A. KEBIJAKAN PUBLIK SEBAGAI TUJUAN}

Kebijakan adalah a means to an end, alat untuk mencapai sebuah tujuan. Kebijakan publik pada akhirnya menyangkut pencapaian tujuan publik. Artinya, kebijakan publik adalah seperangkat tindakan pemerintah yang didesain untuk mencapai hasil-hasil tertentu yang diharapkan oleh publik sebagai konstituen pemerintah. Karenanya, sebuah kebijakan yang baikakan menghindari jebakan ini dengan jalan merumuskan secara eksplisit:

1) Pernyataan resmi mengenai pilihan-pilihan tindakan yang akan dilakukan

2) Model sebab dan akibat yang mendasari kebijakan

3) Hasil-hasil yang akan dicapai dalam kurun waktu tertentu

B. KEBIJAKAN PUBLIK SEBAGAI PILIHAN TINDAKAN YANG LEGAL Pilihan tindakan dalam kebijakan bersifat legal atau otoritatif 
karena dibuat oleh lembaga yang memiliki legitimasi dalam sistem pemerintahan. Keputusan itu mengikat para pegawai negeri untuk menyiapkan rancangan undang-undang atau peraturan pemerintah untuk dipertimbakan oleh parlemen atau mengalokasikan anggaran guna mengimplementasikan program tertentu.

Kebijakan kemudian dapat dilihat sebagai respon atau tanggapan resmi terhadap isu atau masalah publik. Hal ini berarti bahwa kebijakan publik mencakup:

1) Tujuan. Kebijakan publik senantiasa menyangkut pencapaian tujuan pemerintah melalui penerapan sumber-sumber publik.

2) Keputusan. Pembuatan keputusan-keputusan dan pengujian konsekuensi-konsekuensinya.

3) Struktur. Terstruktur dengan para pemain dan langkahlangkahnya yang jelas dan terukur.

4) Tindakan. Tindakan yang bersifat politis yang mengekspresikan pemilihan program-program prioritas lembaga eksekutif.

\section{KEBIJAKAN PUBLIK SEBAGAI HIPOTESIS}

Kebijakan dibuat berdasarkan teori, model atau hipotesis mengenai sebab dan akibat. Kebijakan-kebijakan senantiasa bersandar pada asumsi-asumsi mengenai perilaku. Kebijakan selalu mengandung insentif yang mendorong orang tidak melakukan sesuatu. kebijakan harus mampu menyatukan perkiraan-perkiraan (proyeksi) mengenai keberhasilan yang akan dicapai dan mekanisme mengatasi kegagalan yang mungkin terjadi.

\section{IMPLEMENTASI KEBIJAKAN}

Howlett dan Ramesh (1995) mencatat bahwa implementasi kebijakan sangat dipengaruhi oleh hakekat dan perumusan masalah kebijakan itu, keragaman masalah yang ditangani oleh pemerintah, ukuran kelompok-kelompok sasaran, dan tingkat perubahan perilaku yang diharapkan. Menurut Bridgman dan Davis sebagaimana dikutip 
oleh Suharto (2007), banyak literatur yang menunjukkan prasyarat bagi keberhasilan implementasi kebijakan, antara lain:

a. Didasari oleh teori dan kaidah-kaidah ilmiah mengenai bagaimana program dan peraturan beroperasi.

b. Memiliki langkah-langkah yang tidak terlalu banyak dan kompleks. Semakin banyak dan kompleks langkah-langkah suatu kebijakan, semakin besar kesulitan yang dihadapi kebijakan itu akibat banyaknya kesalahpahaman dan pertentangan yang timbul.

c. Memiliki prosedur akuntabilitas yang jelas. Satu orang atau badan yang kompeten harus diserahi tanggung jawab yang jelas untuk mengontrol dan menjamin keberhasilan implementasi sebuah program.

d. Pihak yang bertanggung jawab memberikan pelayanan harus terlibat dalam perumusan desain kebijakan. Para birokrat ditingkat pelaksaaan sebaiknya memiliki informasi yang lengkap mengenai hakekat, model serta landasan filosofi mengenai kebijakan yang mendasari diberikannya sebuah program.

e. Melibatkan monitoring dan evaluasi yang teratur. Pengawasan dan evaluasi sangat diperlukan agar implementasi kebijakan berjalan efektif.

f. Para pembuat kebijakan harus memberi perhatian yang sungguhsungguh terhadap implementasi seperti halnya terhadap perumusan kebijakan. Artinya, pembuat kebijakan jangan merasa tugasnya telah selesai manakala sebuah kebijakan telah berhasil dirumuskan. Melainkan, harus bekerja terus hingga kebijakan tersebut telah mampu diterapkan melalui serangkaian program yang dirasakan manfaatnya oleh masyarakat.

Fungsi implementasi menurut Suwitri (2008) dalam bukunya yang berjudul Konsep Dasar Kebijakan Publik menyebutkan bahwa suatu upaya yang memungkinkan tujuan-tujuan atau sasaran kebijakan public dapat direalisasikan sebagai outcome atau hasil dari 
kegiatan pemerintah. Karena itu implementasi menyangkut kreativitas dari pelaksanaan kebijakan untuk merancang dan menemukan alat-alat khusus dirancang dan dicari dalam keinginan mencapai tujuan tersebut. Tujuan kebijakan publik diterjemahkan dalam program-program tindakan yang dapat mencapai tujuan.

\section{GAMBAR 1: DIMENSI UNIVERSAL HEALTH COVERAGE}

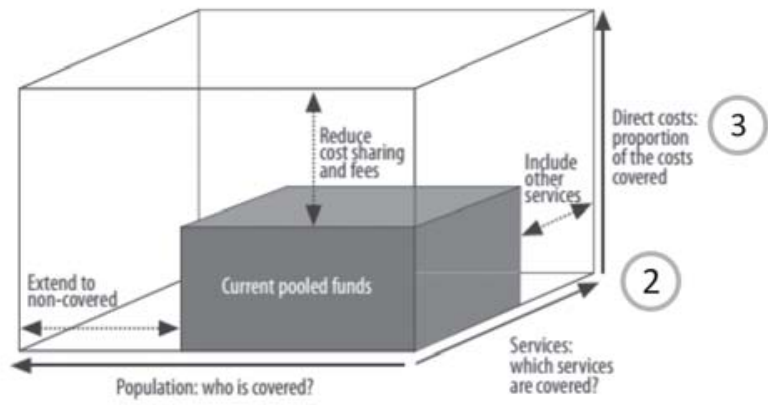

Sumber: WHO, The World Health Report (2010)

\section{UNIVERSAL HEALTH COVERAGE (UHC)}

Mundiharno (2012) menyatakan dalam perspektif jaminan kesehatan, istilah universal coverage memiliki beberapa dimensi. Pertama, dimensi cakupan kepesertaan. Dari dimensi ini universal coverage dapat diartikan sebagai "kepesertaan menyeluruh", dalam arti semua penduduk dicakup menjadi peserta jaminan kesehatan. Dengan menjadi peserta jaminan kesehatan diharapkan mereka memiliki akses terhadap pelayanan kesehatan. Namun tidak semua penduduk yang telah menjadi peserta jaminan kesehatan dapat serta merta mengakses pelayanan kesehatan. Jika di daerah tempat penduduk tinggal tidak ada fasilitas kesehatan, penduduk akan tetap sulit menjangkau pelayanan kesehatan. Oleh karena itu dimensi kedua dari universal health coverage adalah akses yang merata bagi semua penduduk dalam memperoleh pelayanan kesehatan. Secara implicit pengertian ini mengandung implikasi perlu tersedianya 
fasilitas dan tenaga kesehatan agar penduduk yang menjadi peserta jaminan kesehatan benar-benar dapat memperoleh pelayanan kesehatan. Ketiga, universal coverage juga berarti bahwa proporsi biaya yang dikeluarkan secara langsung oleh masyarakat (out of pocket payment) makin kecil sehingga tidak mengganggu keuangan peserta ( $f$ nancial catastrophic) yang menyebabkan peserta menjadi miskin.

WHO merumuskan tiga dimensi dalam pencapaian universal coverage yang digambarkan melalui gambar kubus berikut:

(Lihat gambar 1)

Ketiga dimensi universal coverage menurut WHO adalah (1) seberapa besar persentase penduduk yang dijamin; (2) seberapa lengkap pelayanan yang dijamin, serta (3) seberapa besar proporsi biaya langsung yang masih ditanggung oleh penduduk. Dimensi pertama adalah jumlah penduduk yang dijamin. Dimensi kedua adalah layanan kesehatan yang dijamin, misalnya apakah hanya layanan di rumah sakit atau termasuk juga layanan rawat jalan. Dimensi ketiga adalah proporsi biaya kesehatan yang dijamin. Makin banyak dana yang tersedia, makin banyak pula penduduk yang terlayani, makin komprehensif paket pelayanannya serta makin kecil proporsi biaya yang harus ditanggung penduduk. Alokasi atau pengumpulan dana yang terbatas berpengaruh terhadap komprehensif tidaknya pelayanan yang dijamin serta proporsi biaya pengobatan/perawatan yang dijamin (Mundiharno, 2012).

\section{METODE PENELITIAN}

Dalam penelitian ini, penulis menggunakan penelitian deskriptif kuantitatif. Menurut Sukmadinata penelitian deskriptif bertujuan untuk menggambarkan kejadian pada saat sekarang secara apa adanya. Penelitian deskriptif (descriptive research) adalah suatu metode penelitian yang ditujukan untuk menggambarkan fenomenafenomena yang ada, yang berlangsung pada saat ini atau saat yang lampau. Penelitian ini tidak mengadakan manipulasi atau 
pengubahan pada variabel-variabel tetapi menggambarkan suatu kondisi dengan apa adanya (Sukmadinata, 2011). Sedangkan penelitian kuantitatif menurut Sugiyono (2003) adalah penelitian dengan memperoleh data yang berbentuk angka atau data kualitatif yang diangkakan.

Berdasarkan data BPJS RSUD Morangan dari Januari-September 2014 diketahui jumlah peserta BPJS Kesehatan Kabupaten Sleman sebanyak 54.787. Guna menentukan jumlah sampel penelitian maka ditentukan dengan menggunakan rumus Slovin berikut:

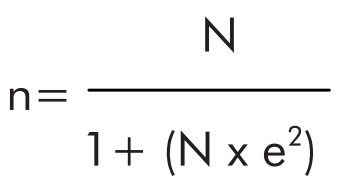

Dimana

$\mathrm{n} \quad=$ Ukuran Sampel

$\mathrm{N}=$ Populasi (dalam penelitian ini jumlah populasinya adalah sebanyak 54.787

e $\quad=$ Prosentasi kesalahan (dalam penelitian ini tingkat kesalahan yang diharapakan sebesar $10 \%$

Berdasarkan rumus slovin di atas maka jumlah sampel dalam penelitian ini adalah 99,817 atau di bulatkan menjadi 100 orang responden penelitian. Teknik yang digunakan unruk menganalisa data dalam penelitian ini adalah teknik analisis deskriptif. Analisis data kuantitatif adalah suatu pengukuran yang digunakan dalam suatu penelitian yang dapat dihitung dengan jumlah satuan tertentu atau dinyatakan dalam angka-angka. Analisis ini meliputi pengolahan data, pengorganisasian data, dan penemuan hasil. Dalam penelitian ini, analisis data kuantitatif yang digunakan adalah analisis angka indeks. Selain menggunakan analisis indeks, dalam penelitian ini juga dilakukan analisis independent sampel t test. Uji ini dilakukan untuk mengetahui apakah ada perbedaan persepsi layanan badan penyelenggara jaminan sosial kesehatan di RSUD Morangan Sleman DIY antara masyarakat yang menerima bantuan 
iuaran dari pemerintah dengan masyarakat bukan peneriman bantuan iuran dari pemerintah. Dalam analisis independent sampel t test ini penyusun menggunakan software SPSS 21.

\section{PEMBAHASAN}

Persepsi Masyarakat Terhadap Layanan Badan Penyelenggara Jaminan Sosial Kesehatan Di RSUD Morangan Sleman DIY

\section{A. PERSEPSI MASYARAKAT TERHADAP PENERIMAAN PENDAFTARAN PESERTA BPJS KESEHATAN}

Setelah dilakukan penelitian terhadap 100 orang responden persepsi masyarakat terhadap penerimaan Pendaftaran Peserta BPJS Kesehatan diperoleh hasil indeks berikut:

\section{TABEL 1: PERSEPSI MASYARAKAT TERHADAP PENERIMAAN PENDAFTARAN PESERTA BPJS KESEHATAN}

\begin{tabular}{llll}
\hline NO & INDIKATOR & NILAI INDEX & KET \\
\hline 1. & Kesiapan pegawai BPIS Kesehatan Kab. Sleman dalam & 3,05 & Baik \\
& penerimaan pendaftaran & & \\
2. & Kecepatan dalam pelayanan pendaftaran & 2,98 & Baik \\
3. & Kemudahan mekanisme pendaftaran & 3,10 & Baik \\
4. & Persyaratan pendaftaran BPJS kesehatan & 2,78 & Baik \\
5. & Kemudahan peralihan menjadi peserta BPJS Kes & 3,38 & Sangat baik \\
6. & Kecepatan untuk menjadi peserta BPJS Kesehatan jika & 3,23 & Baik \\
& sebelumnya menjadi peserta Askes & & \\
& Nilai Index Rata-rata & 3,09 & Baik \\
\hline
\end{tabular}

Sumber: Data diolah (2014)

Tabel di atas memberikan informasi bahwa secara rata-rata variabel melakukan dan atau menerima pendaftaran peserta di BPJS Kabupaten Sleman adalah 3.09 yang termasuk kedalam kategori baik. Namun pada persyaratan pendaftaran BPJS kesehatan memiliki indeks terendah yaitu sebesar 2,78. Hal ini menunjukkan bahwa masyarakat menganggap bahwa Persyaratan pendaftaran BPJS kesehatan masih dianggap sulit oleh masyarakat. 


\section{B. PERSEPSI MASYARAKAT TERHADAP PEMUNGUTAN IURAN BPJS KESEHATAN DI SLEMAN}

Setelah dilakukan penelitian terhadap 100 orang responden persepsi masyarakat terhadap pemungutan iuran BPJS Kesehatan diperoleh hasil indeks berikut:

TABEL 2: PERSEPSI MASYARAKAT TERHADAP PEMUNGUTAN IURAN BPJS KESEHATAN DI SLEMAN

\begin{tabular}{llll}
\hline NO & INDIKATOR & NILAI INDEX & KET \\
\hline 1. & Mekanisme penyetoran & 3,06 & Baik \\
2. & Kemampuan peserta membayarkan iuran & 3,04 & Baik \\
3. & Mekanisme penagihan iuran & 3,00 & Baik \\
4. & Informasi mengenai pembayaran iuran & 2,86 & Baik \\
5. & Sanksi keterlambatan membayar iuran & 2,82 & Baik \\
6. & Sanksi kepada pemberi kerja yangg tidak & 2,94 & Baik \\
& mendaftarkan karyawannya & & \\
& Nilai Index Rata-rata & 2,95 & Baik \\
\hline
\end{tabular}

Sumber: Data diolah (2014)

TABEL 3: PERSEPSI MASYARAKAT TERHADAP

\begin{tabular}{llll}
\hline NO & INDIKATOR & NILAI INDEX & KET \\
\hline 1. & Kelayakan memperoleh bantuan iuran & 3,06 & Baik \\
2. & Pendataan peserta penerima bantuan & 3,06 & Baik \\
3. & Mekanisme penerimaan iuran dari pemerintah & 3,06 & Baik \\
4. & Bantuan iuran dalam memenuhi kebutuhan pembiayaan kesehatan & 3,43 & Sangat baik \\
& Nilai Index Rata-rata & 3,15 & Baik \\
\hline
\end{tabular}

Sumber: Data diolah (2014)

Tabel di atas memberikan informasi bahwa secara keseluruhan BPJS Kesehatan Kabupaten Sleman melakukan pemungutan iuran peserta memiliki indeks 2.95 yang termasuk kedalam kategori baik. Namun pada pelaksanaan Sanksi keterlambatan membayar iuran memiliki indeks terendah yaitu sebesar 2,82. Rendahnya indeks pada pelaksanaan Sanksi keterlambatan membayar iuran ini menunjukkan bahwa sebagian besar masyarakat menganggap bahwa BPJS kesehatan Kabupaten belum menerapkan pemberian sanksi kepada peserta BPJS yang terlambat dalam membayar iuran. 


\section{PERSEPSI MASYARAKAT TERHADAP BANTUAN IURAN PEMERINTAH}

Setelah dilakukan penelitian terhadap 100 orang responden persepsi masyarakat terhadap bantuan iuran dari pemerintah diperoleh hasil indeks berikut:

(lihat tabel 3)

Tabel 3 memberikan informasi bahwa secara keseluruhan BPJS Kesehatan Kabupaten Sleman telah melaksanakan tugas yang terkait dengan peneriman bantuan iuran dari pemerintah dengan baik. Hal ini dikarekan dari empat indikator yang ada nilai indeks yang diperoleh secara-rata-rata sebesar 3,15 yang termasuk kedalam kategori baik. Tabel di atas juga memberikan informasi bahwa dari empat indikator yang ada semua masyarakat telah menganggap jika BPJS Kesehatan Kabupaten Sleman telah melakukan penilain tentang Kelayakan memperoleh bantuan iuran, Pendataan peserta penerima bantuan, Mekanisme penerimaan iuran dari pemerintah dan Bantuan iuran dalam memenuhi kebutuhan pembiayaan kesehatan dalam kotegori baik dengan nilai indeks di atas 3 .

\section{PERSEPSI MASYARAKAT TERHADAP PENGELOLAAN \\ DATA PESERTA}

Setelah dilakukan penelitian terhadap 100 orang responden persepsi masyarakat terhadap pengelolaan data peserta diperoleh hasil indeks berikut:

TABEL 4: PERSEPSI MASYARAKAT TERHADAP

\begin{tabular}{llll}
\hline NO & INDIKATOR & NILAI INDEX & KET \\
\hline 1. & Pendataan peserta BPJS Kesehatan di Sleman & 2,94 & Baik \\
2. & Pengecekan kembali penerima bantuan iuran & 2,80 & Baik \\
3. & Penggunaan kartu BPJS & 3,12 & Baik \\
4. & Informasi sebagai peserta BPJS kesehatan di Sleman & 2,81 & Baik \\
& Nilai Index Rata-rata & 2,91 & Baik \\
\hline
\end{tabular}


Tabel di atas memberikan informasi bahwa secara keseluruhan BPJS Kesehatan Kabupaten Sleman telah melakukan pendataan peserta dengan baik. Hal ini dikarekan dari empat indikator yang ada nilai indeks yang diperoleh secara-rata-rata sebesar 2.91 yang termasuk kedalam kategori baik. Tabel di atas juga memberikan informasi bahwa dari empat indikator yang ada, indikator mengenai informasi sebagai peserta BPJS kesehatan di Sleman memiliki indeks terendah hal ini menggambarkan jika dalam hal Informasi sebagai peserta BPJS kesehatan di Sleman masyarakat belum semuanya memperoleh informasi apakah mereka telah tercatat sebagai anggota BPJS ataukah belum. Hal ini dikarenakan masyarakatlah yang seharusnya aktif mencari informasi bukan dari pihak BPJS

\section{E. PERSEPSI MASYARAKAT TERHADAP MANFAAT BPJS KESEHATAN DI SLEMAN}

Setelah dilakukan penelitian terhadap 100 orang responden persepsi masyarakat terhadap manfaat BPJS Kesehatan di Sleman diperoleh hasil indeks berikut:

\section{TABEL 5: PERSEPSI MASYARAKAT TERHADAP MANFAAT BPJS KESEHATAN DI SLEMAN}

\begin{tabular}{llll}
\hline NO & INDIKATOR & NILAI INDEX & KET \\
\hline 1. & Manfaat menjadi peserta BPJS kesehatan & 3,39 & Sangat baik \\
2. & Ketentuan pembiayaan program kesehatan sosial & 3,31 & Sangat baik \\
3. & Mekanisme pembayaran pelayanan kesehatan oleh BPJS & 3,24 & Baik \\
4. & Kemudahan dalam pencairan biaya & 3,19 & Baik \\
& Nilai Index Rata-rata & 3,28 & Sangat baik \\
\hline
\end{tabular}

Sumber: Data diolah (2014)

Tabel di atas memberikan informasi bahwa secara keseluruhan masyarakat telah merasakan manfaat dengan menjadi peserta BPJS kesehatan. Hal ini dikarekan dari empat indikator yang ada nilai indeks yang diperoleh secara-rata-rata sebesar 3,28 yang termasuk kedalam kategori sangat baik. Tabel di atas juga memberikan informasi bahwa dari empat indikator yang ada, indikator mengenai 
Kemudahan dalam pencairan biaya memiliki indeks terendah yaitu 3.19 hal ini menggambarkan jika dalam hal pencairan biaya, masyarakat masih menganggap ada sedikit kesulitan. Kesulitan ini tentunya berkaitan dengan syarat-syarat yang harus dipenuhi dalam hal pencairan biaya.

\section{F. PERSEPSI MASYARAKAT TERHADAP INFORMASI MENGENAI BPJS KESEHATAN DI SLEMAN}

Setelah dilakukan penelitian terhadap 100 orang responden persepsi masyarakat terhadap informasi mengenai BPJS Kesehatan di Sleman diperoleh hasil indeks berikut:

TABEL 6: PERSEPSI MASYARAKAT TERHADAP INFORMASI MENGENAI

\begin{tabular}{llll}
\hline NO & INDIKATOR & NILAI INDEX & KET \\
\hline 1. & Informasi mengenai hak dan kewajiban peserta & 2,88 & Baik \\
2. & Informasi mengenai ketentuan peserta BPJS & 2,92 & Baik \\
3. & Informasi mengenai prosedur menjadi peserta BPJS & 2,92 & Baik \\
4. & Informasi mengenai prosedur untuk memperoleh pembiayaan & 2,88 & Baik \\
& Nilai Index Rata-rata & 2,90 & Baik \\
\hline & Sumber: Data diolah (2014)
\end{tabular}

Tabel di atas memberikan informasi bahwa secara keseluruhan masyarakat telah menganggap bahwa BPJS Kesehatan Kabupaten Sleman telah memberikan informasi mengenai BPJS dengan baik. Hal ini dikarekan dari empat indikator yang ada nilai indeks yang diperoleh secara-rata-rata sebesar 2,90 yang termasuk kedalam kategori sangat baik. Tabel di atas juga memberikan informasi bahwa dari empat indikator yang ada, indikator mengenai Informasi mengenai prosedur untuk memperoleh pembiayaan memiliki indeks terendah yaitu 2,88 hal ini menggambarkan jika dalam hal informasi mengenai prosedur untuk memperoleh pembiayaan tidak dirasakan oleh masyarakat. 


\section{UJI BEDA IMPLEMENTASI BPJS KABUPATEN SLEMAN} DALAM MENGELOLA JAMINAN KESAHATAN NASIONAL (JKN) DI KABUPATEN SLEMAN

Uji beda dalam penelitian ini dilakukan untuk mengetahui apakah ada perbedaan persepsi antara golongan masyarakat yang menerima bantuan iuran dan golongan masyarakat bukan penerima bantuan iuran mengenai Implementasi BPJS Kabupaten Sleman dalam Mengelola Jaminan Kesahatan Nasional (JKN) di Kabupaten Sleman. Uji beda dalam penelitian ini dilihat dari empat indikator. Hasil uji beda dapat dilihat pada tabel 7 berikut:

TABEL 7: U I BEDA IMPLEMENTASI BPJS KABUPATEN SLEMAN DALAM MENGELOLA JAMINAN KESAHATAN NASIONAL (JKN) DI KABUPATEN SLEMAN

\begin{tabular}{|c|c|c|c|c|}
\hline NO & VARIABEL & SIG & STANDAR & KESIMPULAN \\
\hline 1 & $\begin{array}{l}\text { Pelaksanaan dan Atau } \\
\text { Menerima Pendaftaran } \\
\text { Peserta }\end{array}$ & 0.182 & 0.05 & $\begin{array}{l}\text { Tidak ada perbedaan antara Penerima } \\
\text { Bantuan luran (PBI) dan non Penerima } \\
\text { Bantuan luran (non } \mathrm{PBI} \text { ) berdasarkan } \\
\text { Pelaksanaan dan atau menerima pendaftaran } \\
\text { peserta }\end{array}$ \\
\hline 2 & $\begin{array}{l}\text { Pengelolaan Data Peserta } \\
\text { BPJS Kesehatan Kabupaten } \\
\text { Sleman }\end{array}$ & 0.270 & 0.05 & $\begin{array}{l}\text { tidak ada perbedaan antara Penerima Bantuan } \\
\text { luran (PBI) dan non Penerima Bantuan luran } \\
\text { (PBI) berdasarkan pengelolaan data peserta }\end{array}$ \\
\hline 3 & $\begin{array}{l}\text { Pembayaran Manfaat atau } \\
\text { membiayai Pelayanan } \\
\text { Kesehatan }\end{array}$ & 0.007 & 0.05 & $\begin{array}{l}\text { ada perbedaan antara Penerima Bantuan } \\
\text { luran }(\mathrm{PBI}) \text { dan non Penerima Bantuan luran } \\
\text { (PBI) berdasarkan pembayaran manfaat atau } \\
\text { membiayai pelayanan kesehatan }\end{array}$ \\
\hline 4 & $\begin{array}{l}\text { Pemberian Informasi } \\
\text { Mengenai Penyelenggaraan } \\
\text { BPJS Kesehatan }\end{array}$ & 0.000 & 0.05 & $\begin{array}{l}\text { ada perbedaan signifikan antara Penerima } \\
\text { Bantuan luran (PBI) dan non Penerima } \\
\text { Bantuan luran (non } \mathrm{PBI} \text { ) berdasarkan } \\
\text { pemberian informasi penyelenggaraan BPJS } \\
\text { Kesehatan }\end{array}$ \\
\hline
\end{tabular}

Hasil uji beda di atas menunjukkan bahwa ada perbedaan yang signifikan antara masyarakat penerima bantuan iuran dan masyarakat bukan penerima bantuan iuran berdasarkan pembayaran manfaat atau membiayai pelayanan kesehatan BPJS Kesehatan di Sleman. Perbedaan ini terletak pada dua hal yaitu ketentuan pembiayaan program kesehatan sosial dan mekanisme pembayaran 
pelayanan kesehatan oleh BPJS. Bagi peneriman bantuan iuran tidak akan membayar biaya bulan pada BPJS sedangkan bagi non penerima bantuan iuran mereka di haruskan membayar iuran setiap bulan. Selanjutnya adalah mekanisme pembayaran bagi penerima bantuan iuran tidak perlu membayar sendiri sehingga tidak perlu memikirkan bagaimana mekanisme pembayaran sedangkan bagi non penerima bantuan mereka harus mentaati prosedur pembayaran yang telah ditetapkan oleh pemerintah.

Variabel lain yang memiliki perbedaan adalah variabel pemberian informasi penyelenggaraan BPJS Kesehatan Sleman. Pada uji beda di atas diketahui bahwa ada perbedaan persepsi yang siginifikan antara golongan masyarakat penerima bantuan iuran dan masyarakat bukan penerima bantuan iuran berdasarkan pemberian informasi penyelenggaraan BPJS Kesehatan Sleman. Perbedaan ini terletak pada pertama Informasi mengenai prosedur menjadi peserta BPJS kesehatan. Bagi penerima bantuan iuran informasi mengenai prosedur tidak begitu penting bagi mereka, sehingga mereka menganggap Informasi mengenai prosedur menjadi peserta BPJS kesehatan sudah cukup baik, sedangkan bagi mereka yang tidak menerima bantuan iuran mereka sangat memerlukan informasi mengenai prosedur, sehingga mereka menganggap informasi mengenai prosedur sangat penting namun informasi mengenai prosedur dirasa kurang bagi non penerima bantuan iuran BPJS kesehatan Kabupaten Sleman. Perbedaan kedua adalah Informasi mengenai prosedur untuk memperoleh pembiayaan. Bagi penerima bantuan iuran Informasi mengenai prosedur untuk memperoleh pembiayaan karena mereka telah secara otomatis menjadi peserta dengan dibantu oleh pemerintah. Sedangkan bagi non penerima Informasi mengenai prosedur untuk memperoleh pembiayaan masih dibutuhkan karena mereka ada yang merasa layak menerima bantuan iuran namun tidak terdaftar sebagai penerima bantuan iuran. 


\section{KESIMPULAN}

Berdasarkan hasil penelitian dapat disimpulkan bahwa persepsi masyarakat terhadap layanan badan penyelenggara jaminan sosial kesehatan di RSUD Morangan Sleman DIY berdasarkan Pasal 10 undang-undang No 24 tahun 2011 yang terdiri dari 1) Melakukan dan/atau menerima pendaftaran Peserta, 2) Memungut dan mengumpulkan Iuran dari Peserta dan Pemberi Kerja, 3) Menerima Bantuan Iuran dari Pemerintah, 4) Mengumpulkan dan mengelola data Peserta program Jaminan Sosial, 5) Membayarkan Manfaat dan/ atau membiayai pelayanan kesehatan sesuai dengan ketentuan program Jaminan Sosial dan 6) Memberikan informasi mengenai penyelenggaraan program Jaminan Sosial kepada Peserta dan masyarakat sudah baik dengan rentang nilai indeks 2,78 s/d 3,43.

Hasil penelitian ini juga menyimpulkan bahwa 1) tidak ada perbedaan persepsi yang siginifikan antara golongan masyarakat penerima bantuan iuran dan masyarakat bukan penerima bantuan iuran berdasarkan pelaksanaan dan atau menerima pendaftaran peserta BPJS Kesehatan di Sleman.2) tidak ada perbedaan persepsi yang siginifikan antara golongan masyarakat penerima bantuan iuran dan masyarakat bukan penerima bantuan iuran berdasarkan pengelolaan data peserta BPJS Kesehatan di Sleman. 3) ada perbedaan persepsi yang siginifikan antara golongan masyarakat penerima bantuan iuran dan masyarakat bukan penerima bantuan iuran berdasarkan pembayaran manfaat atau membiayai pelayanan kesehatan BPJS Kesehatan di Sleman dan 4) ada perbedaan persepsi yang siginifikan antara golongan masyarakat penerima bantuan iuran dan masyarakat bukan penerima bantuan iuran berdasarkan pemberian informasi penyelenggaraan BPJS Kesehatan Sleman.

\section{DAFTAR PUSTAKA}

\section{BUKU}

Bridgman, Peter dan Glyn Davis. 2004. The Australian Policy Handbook. Crows 
Nest: Allen and Unwin

Howlett, Michael, dan M. Ramesh. 1995. Studying Public Policy: Policy Cyles and Policy Subsystem. Oxford: Oxford University Press.

Gaffar, Afan. 2009. Politik Indonesia: Transisi Menuju Demokrasi. Yogyakarta: Pustaka Pelajar

Sugiono. 2003, Metode Penelitian Admnistrasi. Bandung: Alfabeta

Suharto, Edi. 2007. Kebijakan Sosial Sebagai Kebijakan Publik. Bandung: Alfabeta

Sukmadinata, N. S. 2011. Metode Penelitian Pendidikan. Cetakan ke 7. Bandung:

Remaja Rosdakarya

Suwitri, Sri. 2008. Konsep Dasar Kebijakan Publik. Semarang: Badan Penerbit UNDIP

\section{JURNAL}

Mundiharno. Peta Jalan Menuju Universal Healtt Converange Jaminan Kesehatan. Jurnal Legislasi Indonesia Vol. 9 No. 2 Juli 2012

Qomaruddin. Badan Hukum Publik Badan Penyelenggara Jaminan Sosial dan Transformasinya Menurut Undang-Undang Nomor 24 Tahun 2011 tentang Badan Penyelenggara Jaminan Sosial. Jurnal Legislasi Indonesia Vol. 9 No. 2. Juli 2012

Rifdan. Implementasi Kebijakan Pemekaran Daerah dalam Mendukung Integrasi Nasional Di Kabupaten Luwu Timur. Jurnal Administrasi Publik, Volume 1 No. 1 Thn. 2010 